\title{
Swelling behavior of heavy crude oil in carbonated water at the presence of $\mathrm{Na}_{2} \mathrm{SO}_{4}$ and $\mathrm{Mg}_{2} \mathrm{SO}_{4}$
}

\author{
Saeed Zaker ${ }^{1,2} \cdot$ Amir Sharafi $^{2} \cdot$ Roohollah Parvizi $^{3} \cdot$ Seyyed Hamid Esmaeili-Faraj ${ }^{4} \cdot$ Ebrahim Ghaseminejad $^{5}$
}

Received: 27 May 2020 / Accepted: 8 June 2020 / Published online: 22 June 2020

(c) The Author(s) 2020

\begin{abstract}
Carbonated water (CW) and low salinity (LS) injection processes are among the most widely investigated method during the past decade due to their unique advantages. Although the results revealed rather efficiency of these two methods, it is reported that using the combination of these two methods can introduce new insight about the smart and newly developed enhance oil recovery processes. Respect to these facts, the current work is aimed to investigate the swelling behavior of heavy crude oil in carbonated water at the presence of $\mathrm{Na}_{2} \mathrm{SO}_{4}$ and $\mathrm{Mg}_{2} \mathrm{SO}_{4}$. In this way, one of the main effective mechanisms through the carbonated water injection which is swelling factor is examined in the presence of two different salts, namely, $\mathrm{Na}_{2} \mathrm{SO}_{4}$ and $\mathrm{Mg}_{2} \mathrm{SO}_{4}$, under different pressures (500-4000 psi) and temperatures (30-80 ${ }^{\circ} \mathrm{C}$ ). The results obtained in this investigation are compared with the previously reported results regarding the carbonated brine (CB) solutions consisted of different salts such as $\mathrm{KCl}, \mathrm{NaCl}, \mathrm{CaCl}_{2}$, and $\mathrm{MgCl}_{2}$ with the same concentration of $15,000 \mathrm{ppm}$. The results not only reveal the possible mechanism behind the swelling factor variation, but also reveal that crude oil and ion type as well as temperature besides the solubility of $\mathrm{CO}_{2}$ in aqueous phase can introduce tremendous influence on the mobility of $\mathrm{CO}_{2}$ molecules and their partitioning from aqueous phase towards the oil phase. Also, the obtained results reveal that the presence of divalent ions can directly affect the crossover pressure toward lower values.
\end{abstract}

Keywords Carbonated brine $\cdot$ Swelling $\cdot$ Bond number $\cdot$ Crude oil $\cdot$ EORs

Roohollah Parvizi

rh_parvizi@yahoo.com

Saeed Zaker

Saeedzaker91@gmail.com

Seyyed Hamid Esmaeili-Faraj

h.esmaeili@shahroodut.ac.ir

Ebrahim Ghaseminejad

ebrahim.q62@gmail.com

1 Islamic Azad University, Science and Research Branch, Tehran, Iran

2 Department of Process Engineering, Research and Development Department, Shazand-Arak Oil Refinery Company, Arak 381314-3553, Iran

3 Department of Petroleum Engineering, Islamic Azad University, Qeshm Branch, Hormozgan, Iran

4 Department of Material and Chemical Engineering, Shahrood University of Technology, Shahrood 3619995161, Iran

5 National Iranian South Oil Company, Ahvaz, Iran

\section{Introduction}

Among the different possible EOR methods, gas injection is the most common method and using carbon dioxide $\left(\mathrm{CO}_{2}\right)$ is the most widely used gas due to several features and concerns existed regarding this gas. In detail, $\mathrm{CO}_{2}$ injection not only can lead to suitable oil recovery but also injecting $\mathrm{CO}_{2}$ into reservoir can manage the $\mathrm{CO}_{2}$ release into environment through $\mathrm{CO}_{2}$ capture which consequently reduces the global warming concern raised by existence of $\mathrm{CO}_{2}$ in atmosphere (Abedini et al. 2014; Lashkarbolooki et al. 2018a). Besides the carbonated brine/water injection, low salinity water injection is the other innovative method for EOR purposes which mostly activates the wettability alteration of the rock surface, although it introduces influences on the other aspects of solution interface and rock surface properties. More recently, due to the advantages of these two methods, a new combination of these two approaches is proposed known as carbonated brine (CB) which utilizes advantages of both methods (Ahmadi et al. 2016; Mosavat and Torabi 2014; Sohrabi et al. 2012). Injection of 
carbonated water not only can lead to higher oil recovery, but also it can retard the $\mathrm{CO}_{2}$ movement toward the surface from the deep of the reservoir resulted in more safe $\mathrm{CO}_{2}$ storage and sequestration (Foroozesh et al. 2016; Mosavat and Torabi 2016). Unfortunately, although this proposed combination moved the researchers toward experimental investigations, no consistent results and mechanisms are proposed (Foroozesh and Jamiolahmady 2016; Riazi 2011; Shakiba et al. 2016). On the other hand, similar to the different areas of sciences, since measuring and experimentation for all the conditions and different types of crude oil is a tedious and expensive approach, modeling and simulation are highly recommended, but, unfortunately, no reliable simulation approach existed regarding this combination due to complexities of this method. For example, Sohrabi et al. (2011b) utilized the ECLIPSE software to simulate the carbonated water injection process, but only overestimated results were obtained. Moreover, Riazi et al. (2011a) proposed a mathematical based method to model the $\mathrm{CO}_{2}$ mass transfer from brine toward crude oil as the main phenomenon during $\mathrm{CB}$ injection besides the other few mathematical equations proposed by different researchers to calculate the solubility of $\mathrm{CO}_{2}$ in crude oil and its effect on the oil swelling factor and viscosity reduction no one leads to reliable results (Barclay and Mishra 2016; Simon and Graue 1965; Welker 1963). Besides the effect of CW on swelling factor, several researchers investigated the effect of different operating and non-operating parameters on possible IFT reduction of solutions comprised of $\mathrm{CO}_{2}$ which revealed no significant IFT reduction using this method (about $5 \mathrm{mN} / \mathrm{m}$ reduction which is insufficient for effective enhanced oil recovery purposes) (Honarvar et al. 2017; Riazi and Golkari 2016; Yang et al. 2005). Also, the performed core flooding (Ahmadi et al. 2016; Foroozesh and Jamiolahmady 2016; Mosavat and Torabi 2014; Shakiba et al. 2016; Sohrabi et al. 2011b, 2012) and micromodel experiments (Riazi et al. 2011b; Sohrabi et al. 2011a) revealed that oil swelling due to $\mathrm{CO}_{2}$ partitioning from aqueous phase toward oil phase is an effective parameter which can, consequently, introduce a reduction in oil viscosity during $\mathrm{CW}$ flooding (Mosavat et al. 2014). Moreover, Abedini et al. (2014) showed that the oil swelling factor of crude oil- $\mathrm{CO}_{2}$ systems increases with the equilibrium pressure and then reduces with further increase in equilibrium pressure. Besides, Lashkarbolooki et al. (2018b) reported no clear and consistent pattern between $\mathrm{CO}_{2}$ solubility in water and swelling of crude oils in the crude oil/CW system. Despite the important role of crude oil swelling during $\mathrm{CW}$ flooding, the effects of temperature and pressure on the swelling behavior of crude oil are still not well understood but certain. Moreover, in addition to the other effective parameters currently discussed through CW injection, Lashkarbolooki et al. (2017) have reported that crude oil type is the other crucial parameter determines the efficiency of CW injection on tertiary oil recovery. In this way, Lashkarbolooki et al. (2018b) examined the possible effects of temperature and pressure on the swelling and Bond number behavior of heavy-acidic crude oil (HACO). Their results demonstrate that two different patterns would be observed regarding the effect of temperature and pressure on the swelling factor of HACO. They also concluded that there is a crossover pressure for swelling factor which leads to a dual effect on the swelling factor behavior. Besides the effect of $\mathrm{CO}_{2}$ existence in aqueous solution, it has been well established that the presence of salinity can introduce positive effect on the aqueous solution for higher oil recovery efficiency (Austad et al. 2010; Lashkarbolooki et al. 2014; Ligthelm et al. 2009; McGuire et al. 2005; Morrow et al. 1998; Tang and Morrow 1997). Respect to the aforementioned shortcomings, it seems that experimental approach is the best way to find the efficiency of this new approach in the current status, especially the swelling factor, since this parameter is the most effective parameter among the possible effective parameters needs to a wide, accurate, and systematic investigation as a function of pressure and temperature especially at the presence of the sulfate ions existed in the formation brine limitedly investigated.

Regarding the aforementioned facts and shortcoming exited regarding both $\mathrm{CW}$ injection and aqueous solution modified by different ions and since no report existed on the effect of divalent ions of $\mathrm{MgSO}_{4}$ and $\mathrm{Na}_{2} \mathrm{SO}_{4}$ concomitant with $\mathrm{CW}$, the effect of ion type on the swelling behavior of crude oil in the presence of $\mathrm{CB}$ as a function of temperature and pressure has investigated in the current investigation. The worth mentioning point is that the current investigation is a complementary phase of previous study performed by Lashkarbolooki et al. (2019) regarding the systems fully saturated with $\mathrm{CO}_{2}$ consisting of $15,000 \mathrm{ppm}$ of $\mathrm{NaCl}, \mathrm{KCl}$, $\mathrm{CaCl}_{2}$ and $\mathrm{MgCl}_{2}$ (named $\mathrm{CNaCl}, \mathrm{CKCl}, \mathrm{CCaCl}_{2}$, and $\mathrm{CMgCl}_{2}$, respectively) at temperatures $(T)$ of 30,50 , and $80{ }^{\circ} \mathrm{C}$ and pressures $(P)$ of $500,1000,2000$, and $4000 \mathrm{psi}$ with especially focus on the two different salts including $\mathrm{MgSO}_{4}$ and $\mathrm{Na}_{2} \mathrm{SO}_{4}$.

\section{Materials and experimental procedure}

\section{Materials}

A heavy-acidic crude oil (HACO) type as previously used by Lashkarbolooki et al. (2019) was provided from southern Iranian oilfields (total acid number of $1.5 \mathrm{mg} \mathrm{KOH} / \mathrm{g}$ and $\mathrm{API}^{\circ}$ of 21.5) and used as the sample crude oil. Besides, the used aqueous solutions for carbonated water preparation were consisted of two different salts of magnesium sulfate heptahydrate $\left(\mathrm{MgSO}_{4} \cdot 7 \mathrm{H}_{2} \mathrm{O}\right)(\mathrm{MW}$ of $246.48 \mathrm{~g} /$ mol) and sodium sulfate $\left(\mathrm{Na}_{2} \mathrm{SO}_{4}\right)$ (MW of $142.04 \mathrm{~g} /$ 
mol) with concentration of 15000 ppm [Merck, Germany (Purity $>99 \%$ ) used without any further purification]. In addition, the carbonated water was prepared by $\mathrm{CO}_{2}$, purchased from Abughadareh Co., Iran (purity $>99.9 \%$ ).

\section{Experimental procedure}

\section{Swelling and Bond number measurements}

A previously validated and established high temperature-high pressure pendant drop interfacial tension equipment (Atiyeh Pouyandegan Exir Technologies Co. (Apex technologies), Arak, Iran) (see Fig. 1) is used to measure the swelling factor through the current investigation. In brief, it is possible to inject the bulk and drop at desired pressure and temperature in pendant or rising positions. Besides, the measuring chamber (total volume of $15 \mathrm{cc}$ ) is equipped with two sapphire sight glasses capable of the operator to monitor the inside content of the chamber using a CCD camera equipped with macro lens (Computar, Japan) which dispatches the images to online software. Besides the main chamber, a twin accumulator block existed which separately holds the bulk and drop phases to inject them into the measuring chamber. The temperature of both measuring chamber and accumulators is controlled using elements coupled with PT-100 thermocouple with accuracy of about $0.1{ }^{\circ} \mathrm{C}$. In addition to temperature, the pressure of the system was monitored using a digital pressure transmitter (WIKA, Germany). After tuning the pressure and temperature and forming the drop at the tip of the nozzle, the images of the formed drop which were captured using CCD camera instantly measure the volumes of the drops which are capable of the operator to calculate the swelling factor $\left(\mathrm{SF}=\frac{V_{t}}{V_{0}}\right)$ and $\Delta$

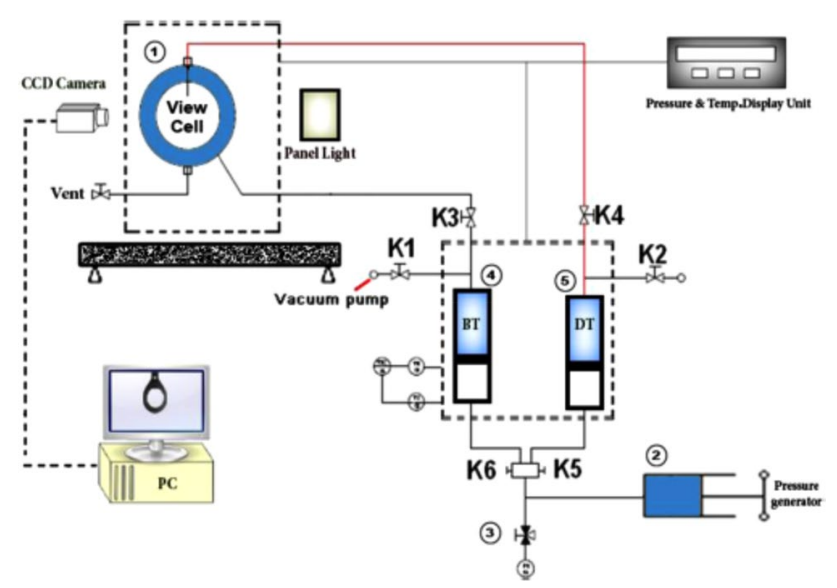

Fig. 1 The used IFT measurement Apparatus (1, view cell; 2, pressure generator; 3 , pressure manometer; 4 , bulk tank; 5, drop tank) (Zolghadr et al. 2013)
Bond number $\left.{ }_{\Delta}\right)$ where $V_{t}$ is the crude oil drop volume at time $t, V_{0}$ is the crude oil drop volume at initial time, $\mathrm{BN}_{t}$ is the Bond number at time $t$, and $\mathrm{BN}_{0}$ is Bond number at initial time.

\section{Results and discussion}

\section{Evaluation of swelling and Bond number behaviors of $\mathrm{HACO} / \mathrm{CNa}_{2} \mathrm{SO}_{4}$ and $\mathrm{CMgSO}_{4}$}

In the first stage, the swelling and $\Delta$ Bond number variations of the first binary system namely $\mathrm{HACO} / \mathrm{CNa}_{2} \mathrm{SO}_{4}$ as a function of time and pressure (500-4000 psi) were examined under different isotherms of 30,50 , and $80{ }^{\circ} \mathrm{C}$ (see Fig. 2). Before any measurements, to ensure about the effect of ions on the swelling factor, several measurements were carried out in the absence of $\mathrm{CO}_{2}$ in the aqueous phase which revealed no swelling can be observed for the system contain no dissolved $\mathrm{CO}_{2}$. A glance into the results depicted in Fig. 2 reveals that at a specific isotherm, an increase in the pressure may lead to an increase in the swelling factor. In more details, the results demonstrated that for isotherm of $30^{\circ} \mathrm{C}$, increasing the pressure from 500 psi to 4000 psi enhances the swelling factor from 1.03 to 1.11 which means three times larger swelling factor. In addition, from the closer examination in the results depicted in Fig. 2, one can conclude that there is a direct relation between the temperature and swelling factor. In details, increasing the temperature from $30{ }^{\circ} \mathrm{C}$ to $80{ }^{\circ} \mathrm{C}$ for pressure of $4000 \mathrm{psi}$, an increase in the swelling factor from 1.11 to 1.24 which means two times enhancement in swelling factor would be obtained. Moreover, comparing the swelling factor of two pressures including 500 and 1000 psi, one can conclude that as the temperature enhances, the swelling factor of these two isobars are getting close to each other, while for pressures of 2000 and $4000 \mathrm{psi}$, the trend is reversed.

The overall observed swelling factor enhancement regardless of temperature and pressure for all the studied systems can be related to this fact that the presence of $\mathrm{CO}_{2}$ in the aqueous solution can lead to partitioning of $\mathrm{CO}_{2}$ toward the crude oil which consequently leads to swelling of the oil drop. In other words, it can be concluded that the swelling of the crude oil in the presence of $\mathrm{CW}$ occurs caused by the partitioning of $\mathrm{CO}_{2}$ from the $\mathrm{CW}$ phase by diffusion and dissolution of $\mathrm{CO}_{2}$ into the oleic phase. Furthermore, the higher swelling factor observed for higher pressures can be related to the direct relation existed between the pressure and capability of aqueous solution to dissolve the $\mathrm{CO}_{2}$. In detail, as the pressure enhances, the aqueous solution capability to dissolve $\mathrm{CO}_{2}$ enhances which means that higher $\mathrm{CO}_{2}$ content would be available to penetrate into the oil drop which 
Fig. 2 Dynamic swelling factor of crude oil in the presence of $15,000 \mathrm{ppm}$ of $\mathrm{Na}_{2} \mathrm{SO}_{4}$ at temperature of $\mathbf{a} T=30^{\circ} \mathrm{C}, \mathbf{b}$ $50{ }^{\circ} \mathrm{C}$, and $\mathbf{c} 80^{\circ} \mathrm{C}$
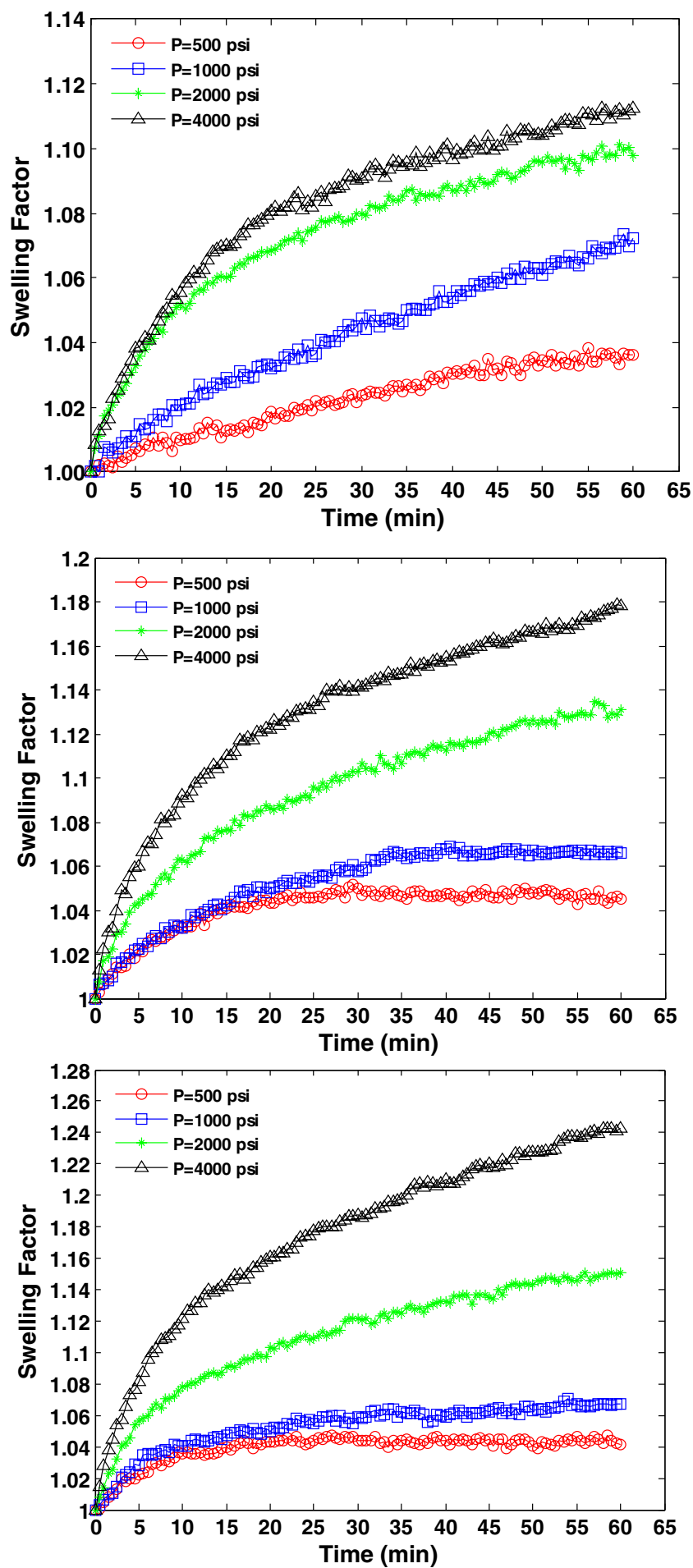

since temperature has a reverse effect on the solubility of gases in water. Therefore, this is the net effect of these two competing factors, dictate if the temperature leads to larger swelling factor or not. Regarding this fact, it seems that for all of the studied temperatures, the first effect is dominant. However, closer examination in Fig. 2 also demonstrates that as the temperature enhances the swelling factor of two lead to a reduction in $\mathrm{CO}_{2}$ solubilization in aqueous solution, 
isobars of 500 psi and 1000 psi getting closer to each other, while for pressures of $2000 \mathrm{psi}$ and $4000 \mathrm{psi}$, this trend is different and temperature enhancement increases the difference existed between the swelling factors of these two isobars. In sum up, according to these findings, it can be concluded that the examined system of $\mathrm{HACO} / \mathrm{CNa}_{2} \mathrm{SO}_{4}$ may have a cross over pressure of about $2000 \mathrm{psi}$, since the effect of temperature is different on the swelling factor variation for pressures above the 2000 psi.

In the second stage of this investigation, the effects of pressure and temperature on the Bond number ratio of the $\mathrm{HACO} / \mathrm{CNa}_{2} \mathrm{SO}_{4}$ were examined (see Fig. 3). The obtained results revealed that for temperature of $30{ }^{\circ} \mathrm{C}$, increasing the pressure led to a reduction in Bond number ratio for all the studied isobars. However, for the other two examined isotherms of 50 and $80^{\circ} \mathrm{C}$, the effect of pressure on the Bond number ratio is more complicated than $30{ }^{\circ} \mathrm{C}$ isotherm. In details, for isotherm of $50^{\circ} \mathrm{C}$, although for all of the examined pressures of 1000, 2000, and $4000 \mathrm{psi}$, the Bond number ratio is decreasing similar to the $30{ }^{\circ} \mathrm{C}$ isotherm; for pressure of $500 \mathrm{psi}$, two phases of variation can be observed.

In details, for this pressure and before period of $30 \mathrm{~min}$, slight decreasing trend can be observed, while for period of after $30 \mathrm{~min}$, the trend of variation is reversed. For a better clarification regarding the obtained results, the ultimate values for Bond number ratio and swelling factor are depicted in Fig. 4. Mining into the results depicted in Fig. 4 revealed that for $\mathrm{CNa}_{2} \mathrm{SO}_{4} / \mathrm{HACO}$, there is a sharp crossover pressure of around $1000 \mathrm{psi}$.

In details, it is obvious that for the aforementioned system inverse swelling and $\Delta$ Bond number trends could be observed for two different regions which can be categorized as the below cross over pressure (BCP) and above the crossover pressure (ACP) regions. In the BCP, swelling of crude oil drop decreases with temperature, while in the ACP region, the trend get reversed [crossover pressure $\left(P_{\mathrm{CO}}\right)$ of about $1000 \mathrm{psi}$. This observed trend can be related to the mechanism previously proposed by Lashkarbolooki et al. (2019) that in the first region (i.e., $P<P_{\mathrm{CO}}$ ), $\mathrm{CO}_{2}$ solubility in aqueous phase is the controlling factor, while in the second region (i.e., $P>P_{\mathrm{CO}}$ ), mobility and loosening of the $\mathrm{H}$ Bond between water molecules have the dominant impact on partitioning of $\mathrm{CO}_{2}$ (Lashkarbolooki et al. 2018b). In more details, there is a direct relation between gas dissolution in liquids and the interaction between the molecules of gas and liquid molecules. However, this is the formation of carbonic acid that led to dissolution of $\mathrm{CO}_{2}$ in water which rise from the chemical structure and its ability to react with $\mathrm{H}_{2} \mathrm{O}$. The point regarding the $\mathrm{CO}_{2}$ dissolution into the water is that no strong attraction would be obtained between these two chemicals which, as a consequence, the $\mathrm{CO}_{2}$ molecules can easily come out of $\mathrm{CW}$ solution. The solubility of $\mathrm{CO}_{2}$ in
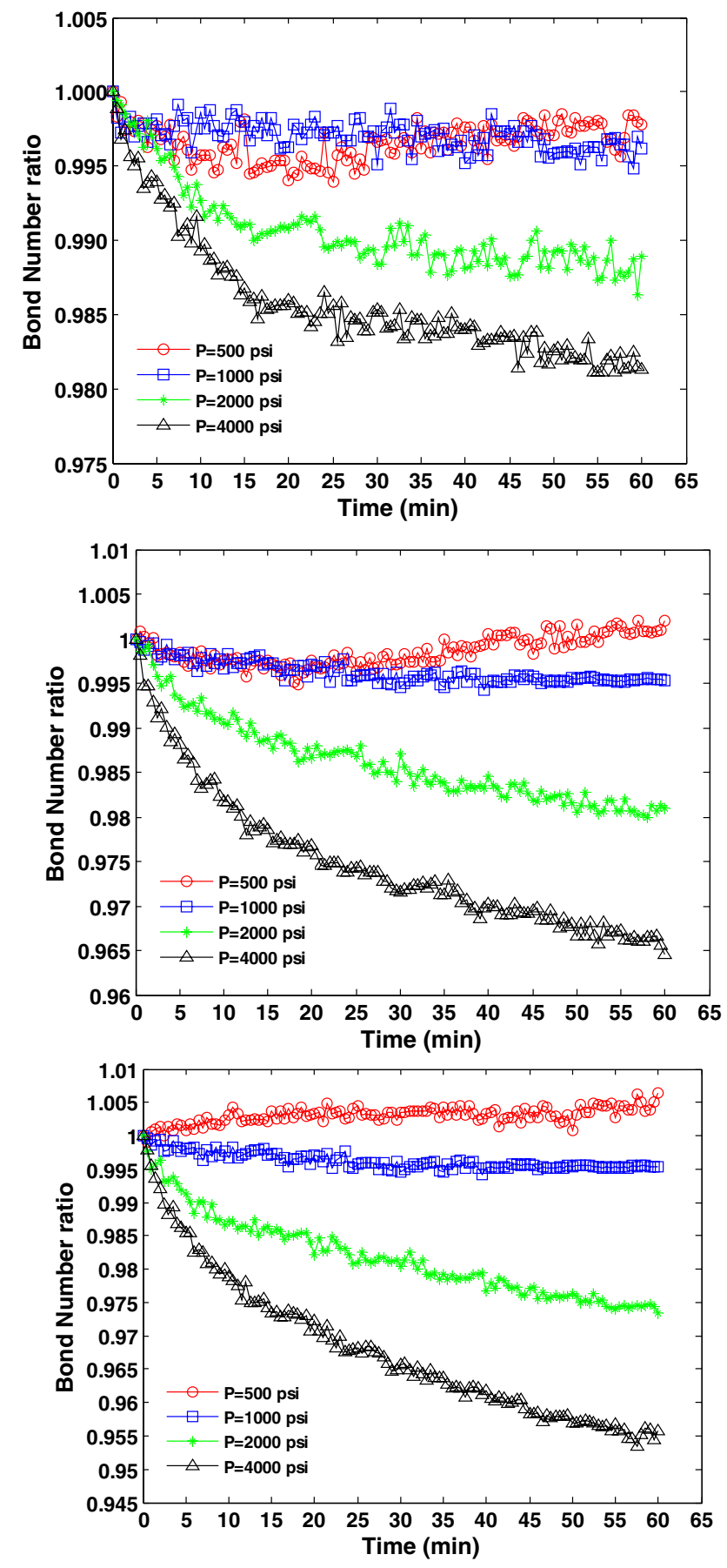

Fig. 3 Dynamic Bond number ration of crude oil in the presence of $15,000 \mathrm{ppm}$ of $\mathrm{Na}_{2} \mathrm{SO}_{4}$ at temperature of $\mathbf{a} T=30^{\circ} \mathrm{C}, \mathbf{b} 50{ }^{\circ} \mathrm{C}$, and $\mathbf{c}$ $80{ }^{\circ} \mathrm{C}$

DW increases when they have functional groups enables to form $\mathrm{H}$ Bonds with water. For $\mathrm{CO}_{2}$ partitioning from $\mathrm{CW}$ phase to the crude oil phase, there is very little interaction between $\mathrm{CO}_{2}$ particles; hence, no solute-solute interaction needs to be broken, while water-water interaction (i.e., $\mathrm{H}$ Bond) have to be broken in order to partition $\mathrm{CO}_{2}$ from

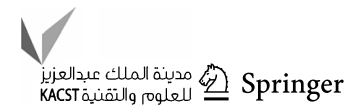



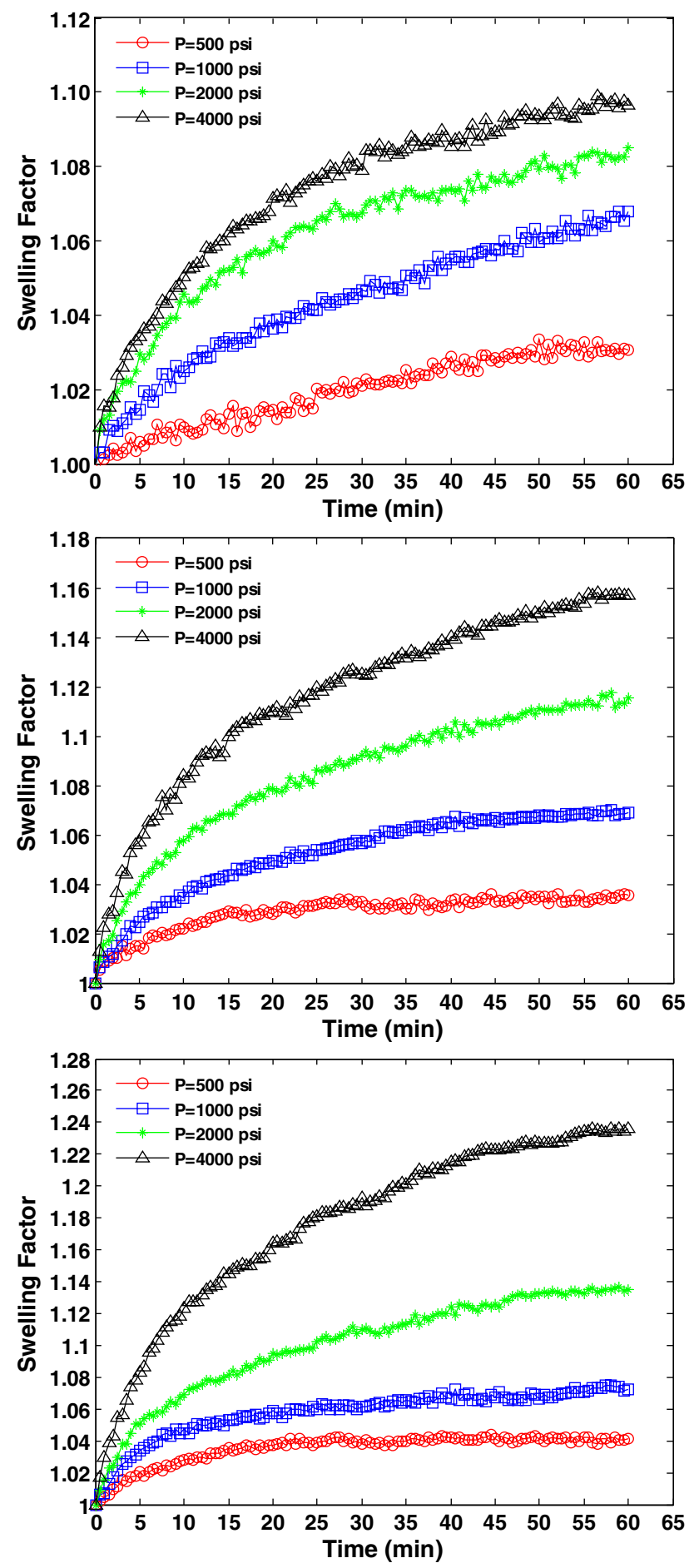

Fig. 4 Dynamic swelling factor of crude oil in the presence of $15,000 \mathrm{ppm}$ of $\mathrm{MgSO}_{4}$ at temperature of $\mathbf{a} T=30^{\circ} \mathrm{C}$, b $50{ }^{\circ} \mathrm{C}$, and $\mathbf{c}$ $80^{\circ} \mathrm{C}$

the aqueous phase to the crude oil phase (Lashkarbolooki et al. 2018b).

In the next stage of this investigation, dynamic swelling factor and Bond number ratio for carbonated water consisted of 15,000 $\mathrm{ppm}$ of $\mathrm{MgSO}_{4}$ under different pressures and temperatures were examined. Similar to the results obtained for $\mathrm{Na}_{2} \mathrm{SO}_{4}$, as the pressure increases from 500 psi to $4000 \mathrm{psi}$, the swelling factor was increased for all the examined isotherms. However, comparing the results depicted in Figs. 2, 3, 4 and 5, demonstrated that the swelling factor as a function of pressure is lower for $\mathrm{MgSO}_{4}$ compared with $\mathrm{Na}_{2} \mathrm{SO}_{4}$. In addition, the results revealed that the effect of temperature for swelling factor reduction for pressure of $2000 \mathrm{psi}$ is sharper than that observed for $\mathrm{Na}_{2} \mathrm{SO}_{4}$ although the effect of this parameter is less than that obtained for $\mathrm{Na}_{2} \mathrm{SO}_{4}$. In addition, it seems that not only in the case of $\mathrm{MgSO}_{4}$ respect to $\mathrm{Na}_{2} \mathrm{SO}_{4}$, the swelling factor is less than that observed for $\mathrm{Na}_{2} \mathrm{SO}_{4}$, but also the observed slope is moderate compared with the slope of $\mathrm{Na}_{2} \mathrm{SO}_{4}$. The interesting point is that for both cases of $\mathrm{MgSO}_{4}$ and $\mathrm{Na}_{2} \mathrm{SO}_{4}$, even after $1 \mathrm{~h}$ measurement from the beginning of the test, some drop volume did not reach the equilibrium condition. This phenomenon is more considerable at higher temperature and pressure conditions (see Figs. 2 and 4). As can be seen from Figs. 2 and 4 , at isobaric of $4000 \mathrm{psi}$, an increase in temperature from $30{ }^{\circ} \mathrm{C}$ to $80{ }^{\circ} \mathrm{C}$ increases the swelling factor tremendously with no obvious plateau which can be due to this fact that the $\mathrm{CO}_{2}$ transfer between the aqueous phase and the oil phase is slow and equilibrium state could not be reached (Fig. 6).

In the next stage, the variation of Bond number ratio as a function of pressure at different isotherms was investigated for $\mathrm{MgSO}_{4}$ which was rather different from that observed for $\mathrm{Na}_{2} \mathrm{SO}_{4}$. In details, for pressures of $2000 \mathrm{psi}$ and $4000 \mathrm{psi}$, the Bond number ratio variation is below 1 for all the examined isotherms similar to $\mathrm{Na}_{2} \mathrm{SO}_{4}$, while for pressures of $1000 \mathrm{psi}$ and $500 \mathrm{psi}$, the Bond number ratio shift toward 1 and even getting larger than 1 for pressure of $500 \mathrm{psi}$ and temperatures higher than $30^{\circ} \mathrm{C}$. For a better clarification, similar to the $\mathrm{Na}_{2} \mathrm{SO}_{4}$, the ultimate values for swelling factors and Bond number ratio values as a function of temperature and pressure are depicted in Fig. 7. A close examination into this figure can illustrate that although no cross over pressure can be observed for swelling factor, a sharp and obvious cross over pressure of about 1000 psi can be observed considering the ultimate Bond number ratio values. Similar to those obtained for $\mathrm{Na}_{2} \mathrm{SO}_{4}$, the observed trend can be related to the mechanism previously proposed by Lashkarbolooki et al. (2019) that in the first region (i.e., $P<P_{\mathrm{CO}}$ ), $\mathrm{CO}_{2}$ solubility in aqueous phase is the controlling factor, while in the second region (i.e., $P>P_{\mathrm{CO}}$ ), mobility and loosening of the $\mathrm{H}$ Bond between water molecules has the dominant impact on partitioning of $\mathrm{CO}_{2}$ (Lashkarbolooki et al. 2018b). Similarly, Zhao et al. (2015) revealed that $\mathrm{CO}_{2}$ solubility in the aqueous phase shows different trends in 

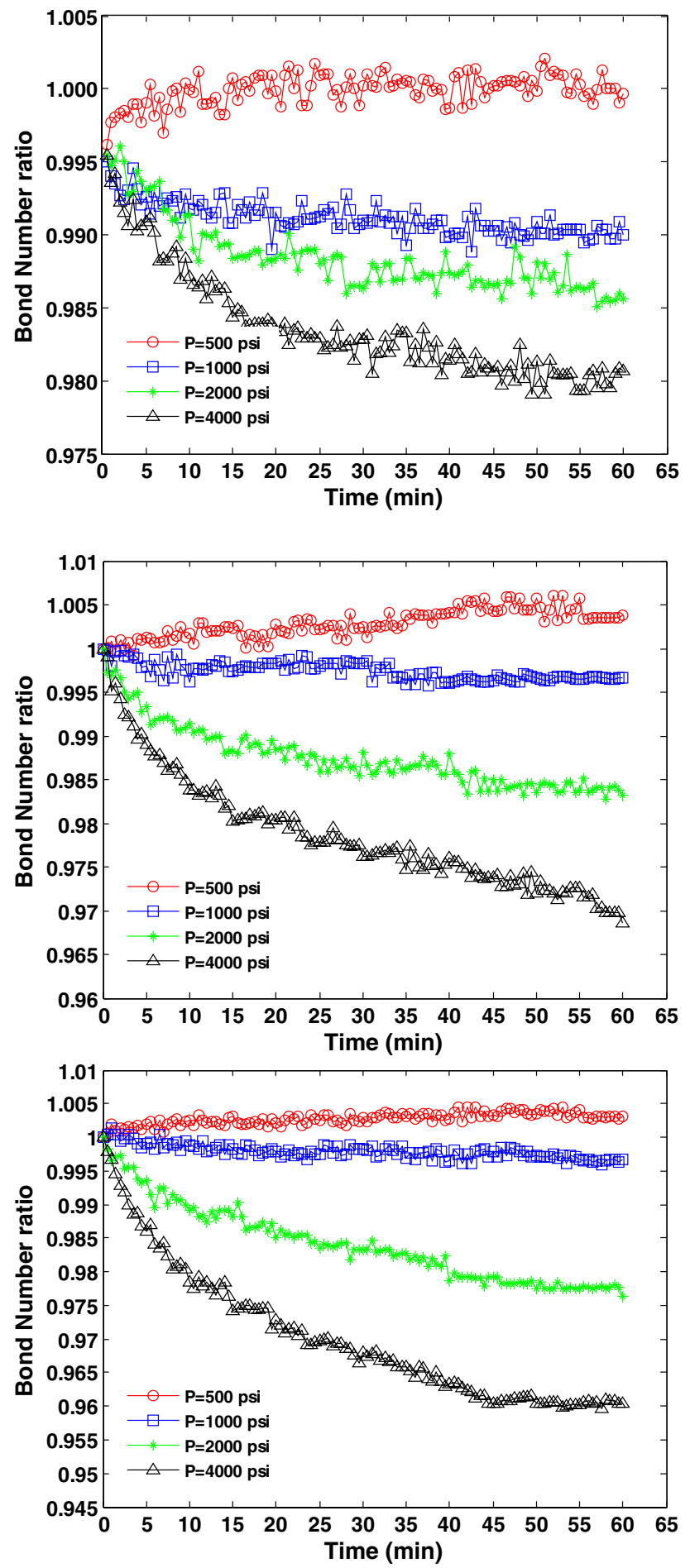

Fig. 5 Dynamic Bond number ration of crude oil in the presence of $15,000 \mathrm{ppm}$ of $\mathrm{MgSO}_{4}$ at temperature of a $T=30^{\circ} \mathrm{C}, \mathbf{b ~} 50^{\circ} \mathrm{C}$, and $\mathbf{c}$ $80{ }^{\circ} \mathrm{C}$

two distinct regions. In region I, the $\mathrm{CO}_{2}$ solubility in the aqueous phase decreases monotonically as a function of temperature, reversely at a given pressure in region II, the $\mathrm{CO}_{2}$ solubility increases (Duan et al. 2006).

\section{Comparison between the studied carbonated brines and carbonated water}

In the next stage of this investigation, the effect of salt dissolution in the carbonated water on the swelling factor and Bond number ratio was investigated. In this regard, the obtained results of these two parameters for both carbonated brine $(\mathrm{CB})$ and carbonated water $(\mathrm{CW})$ are depicted in Figs. 8 and 9. Mining into the results depicted in these two figures demonstrated that dissolution of salts regardless of which salt is dissolved led to two different phenomena including reduction in swelling factor and enhancement in Bond number ratio and shifting the cross over pressure toward lower values. In details, it seems that dissolution of salts into the $\mathrm{CW}$ had a undesired effect on the swelling factor which may be due to this fact that the presence of ions on the carbonated water may form a strong bonding to the $\mathrm{CO}_{2}$ preventing the easier movement of $\mathrm{CO}_{2}$ toward the oil interface to be dissolved in the oil drop.

This observed trend is in agreement with the results reported by Lashkarbolooki et al. (2019) regarding the effect of ion types on the swelling factor. They have reported that existence of monovalent ions, i.e., $\mathrm{Na}^{+}$and $\mathrm{K}^{+}$in the carbonated brine may lead to an enhancement on the crossover pressure, while the existence of divalent ions such as $\mathrm{Ca}^{2+}$ and $\mathrm{Mg}^{2+}$ can reduce the crossover pressure of $\mathrm{CCaCl}_{2}$ and $\mathrm{CMgCl}_{2}$. The worth mentioning point is that Lashkarbolooki et al. (2019) have reported that the observed trend can be related to the direct effect of salts on the solubility of $\mathrm{CO}_{2}$ in the aqueous solutions. However, in the current study, considering the solubility of $\mathrm{CO}_{2}$ in the brine solutions using Duan model (Duan et al. 2006) (see Fig. 10), it is completely obvious that the solubility of $\mathrm{CO}_{2}$ in the $\mathrm{MgSO}_{4}$ is larger than the value of $\mathrm{CO}_{2}$ solubility in $\mathrm{Na}_{2} \mathrm{SO}_{4}$, but the swelling factor for $\mathrm{MgSO}_{4}$ is lower than $\mathrm{Na}_{2} \mathrm{SO}_{4}$. This observed trend can be related to this fact that although the presence of $\mathrm{MgSO}_{4}$ may lead to higher solubility of $\mathrm{CO}_{2}$ in the brine solution compared with the $\mathrm{Na}_{2} \mathrm{SO}_{4}$, the bonding between the $\mathrm{MgSO}_{4}$ and $\mathrm{CO}_{2}$ in the aqueous solution is stronger than $\mathrm{Na}_{2} \mathrm{SO}_{4}$ prevents easy movement of $\mathrm{CO}_{2}$ molecule into the oil drop surface and consequent swelling. In other words, stronger bonding between $\mathrm{CO}_{2}$ and $\mathrm{MgSO}_{4}$ which led to higher solubility of $\mathrm{CO}_{2}$ compared with the $\mathrm{Na}_{2} \mathrm{SO}_{4}$ act as a preventing parameter reduces the swelling factor.

\section{Conclusions}

In the current experimental investigation, the effect of pressure and temperature on the swelling factor and Bond number ratio of carbonated water including $15,000 \mathrm{ppm}$ of $\mathrm{MgSO}_{4}$ and $\mathrm{Na}_{2} \mathrm{SO}_{4}$ were investigated. Considering the

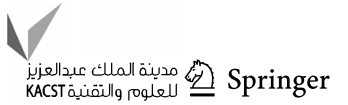




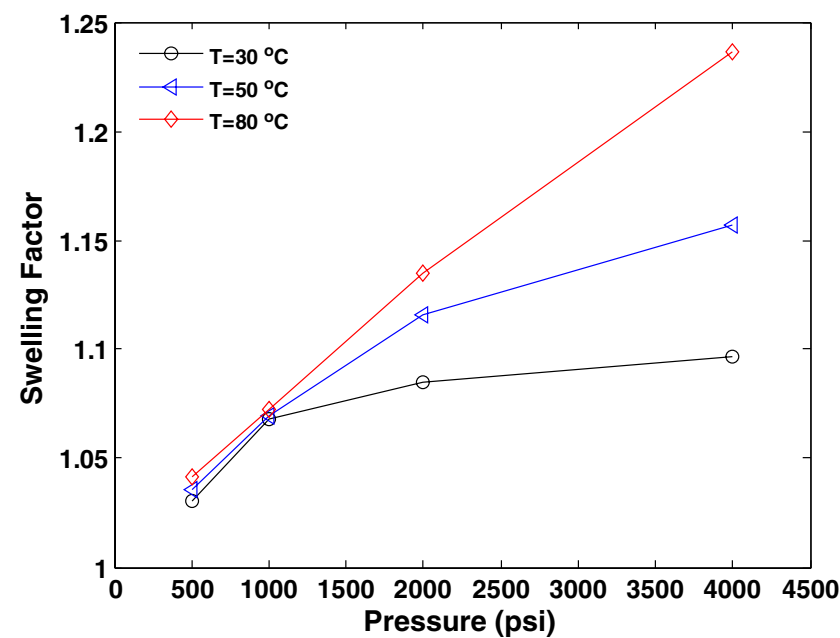

(a)

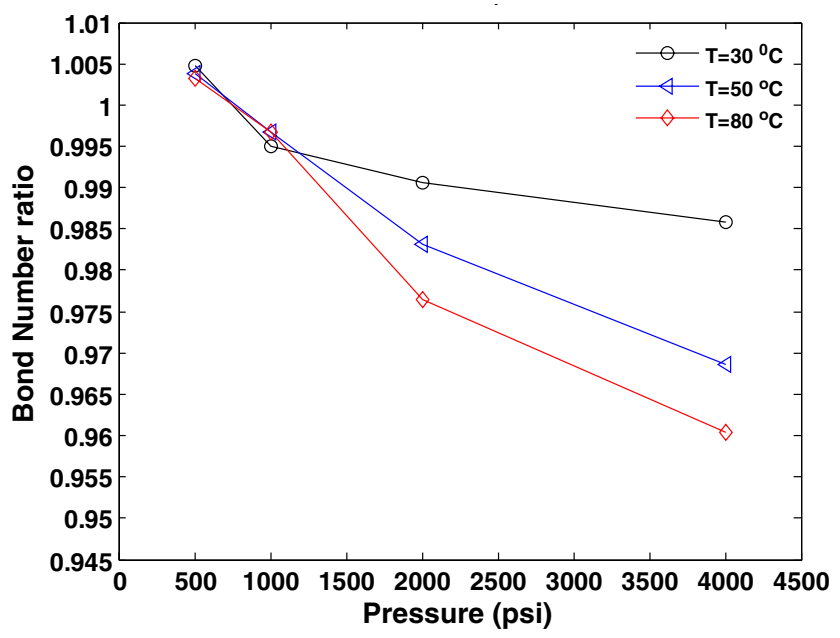

(b)

Fig. 6 a Swelling factor and $\mathbf{b}$ Bond number ratio after $1 \mathrm{~h}$ at different temperature and pressure condition for case of $15,000 \mathrm{ppm}^{\circ} \mathrm{MgSO}_{4}$

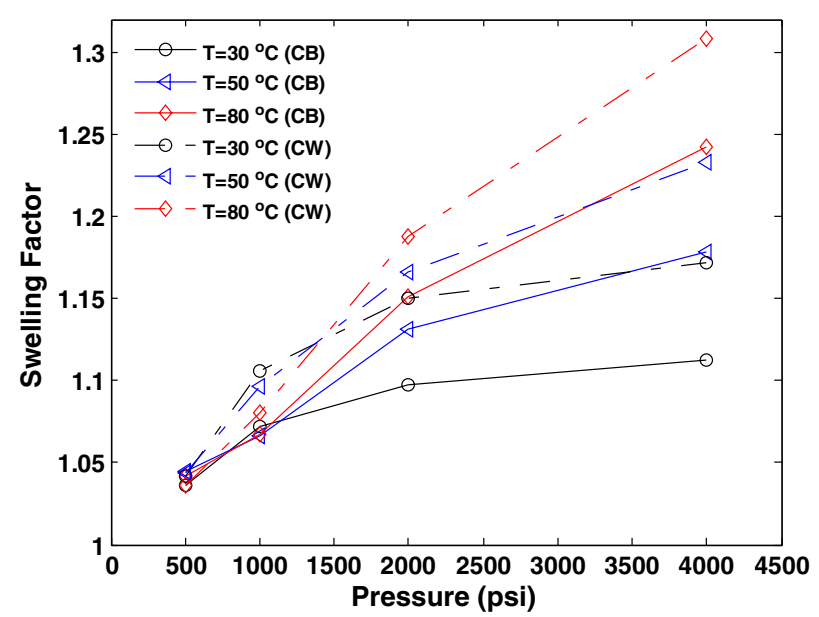

(a)

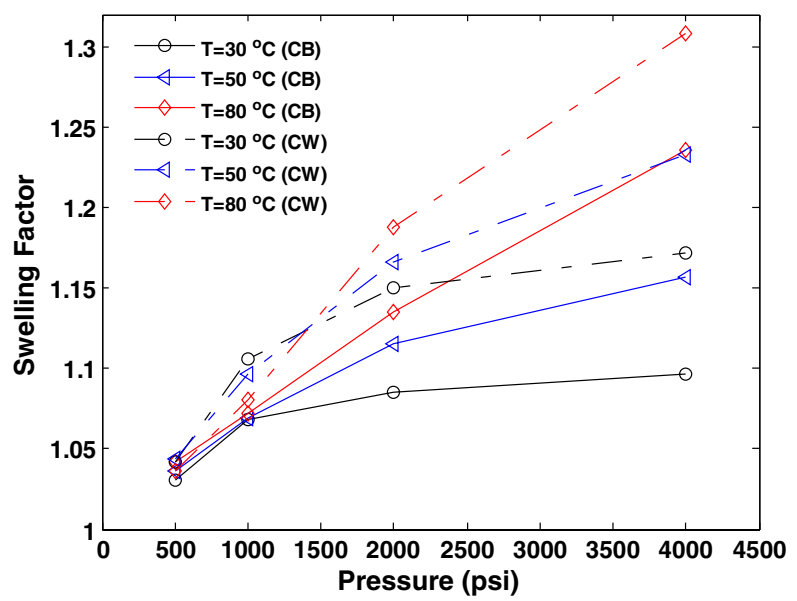

(b)

Fig. 7 Comparison of swelling factor in the presence and absence of $\mathbf{a} \mathrm{Na}_{2} \mathrm{SO}_{4}$ and $\mathbf{b ~} \mathrm{MgSO}_{4}$ at different temperature and pressure condition

performed measurements, one can conclude the following outcome:

- Pressure and temperature can introduce direct effects on the swelling factor and Bond number ratio. Pressure has a simple and direct relation on the swelling factor, since it directly affects the solubility of $\mathrm{CO}_{2}$ in the aqueous solution, while the effect of temperature was more complicated.

- Regarding the examined pressure and temperatures, two different trends were observed for the effects of these two operational parameters called cross over pressure. Crossover pressure point was defined as a point which below and above this point, two different trends on the swelling factor and Bond number ratio can be observed regardless of the used salts. This point which was about 1000 psi revealed that for the pressures lower than this value (i.e., $P<P_{\mathrm{CO}}$ ), $\mathrm{CO}_{2}$ solubility in the aqueous phase is the dominant parameter dictates the swelling factor is increasing or decreasing, while in the region which the pressure is larger than this point (i.e., $\left.P>P_{\mathrm{CO}}\right)$, mobility and loosening of $\mathrm{H}$ bond between water molecules are the most effective and dominant factors which tremendously affect the partitioning of $\mathrm{CO}_{2}$ into crude oil phase.

- The obtained results demonstrated that the presence of salts can introduce direct effect on the swelling factor of HACO. 


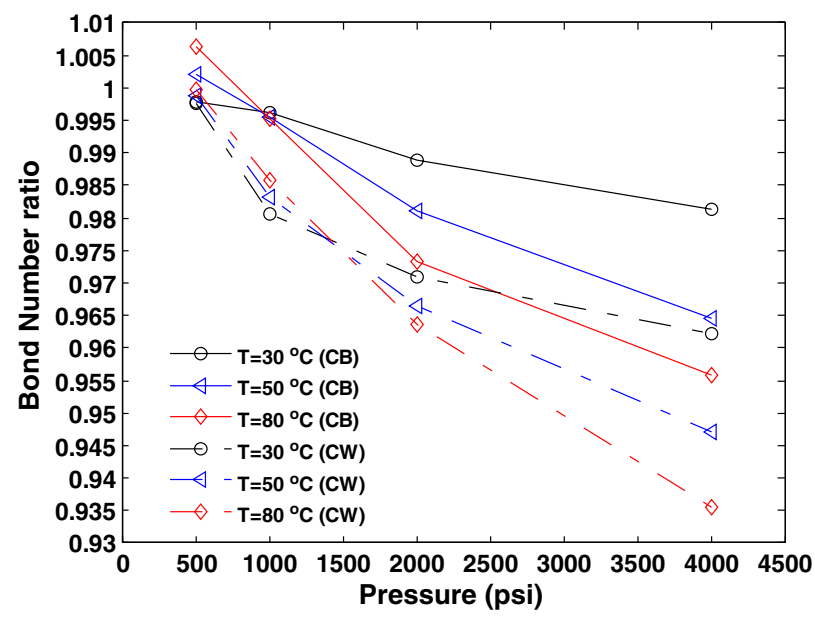

(a)

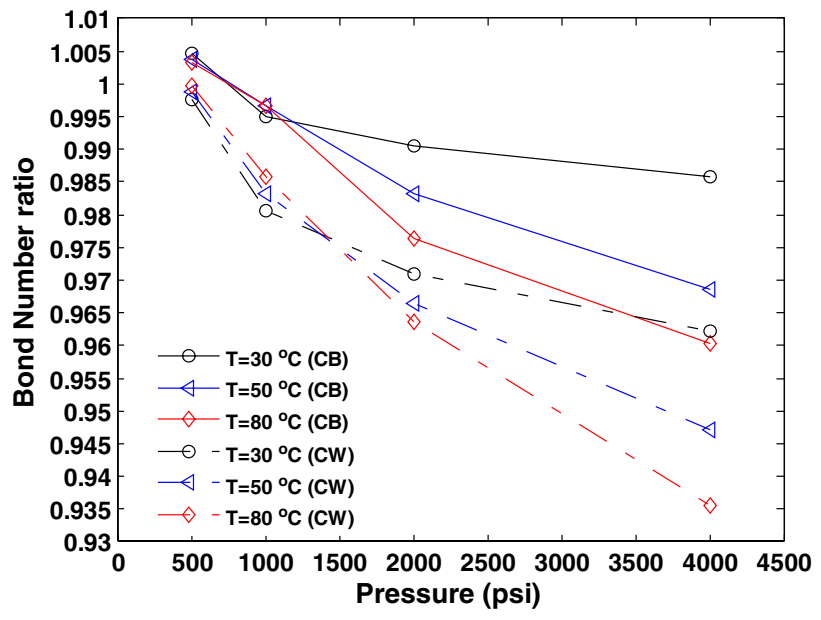

(b)

Fig. 8 Comparison of Bond number ratio in the presence and absence of $\mathbf{a} \mathrm{Na}_{2} \mathrm{SO}_{4}$ and $\mathbf{b} \mathrm{MgSO}_{4}$ at different temperature and pressure condition

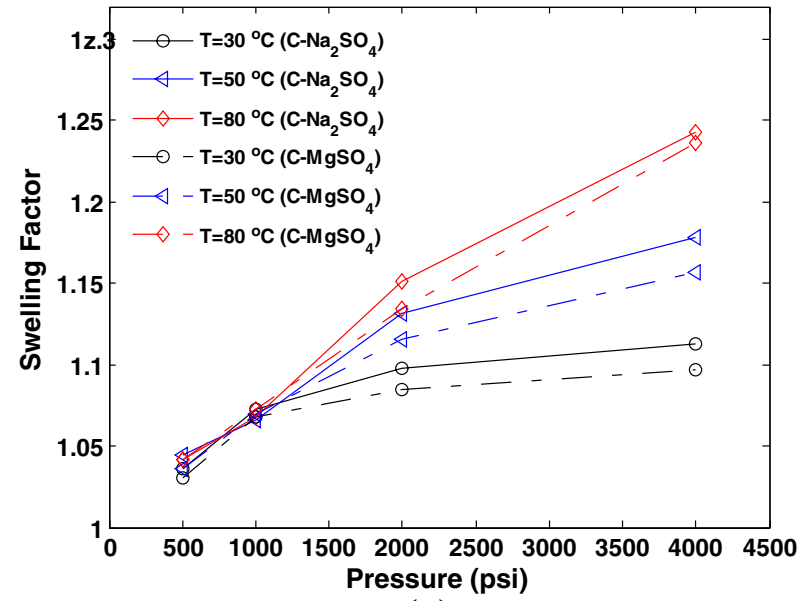

(a)

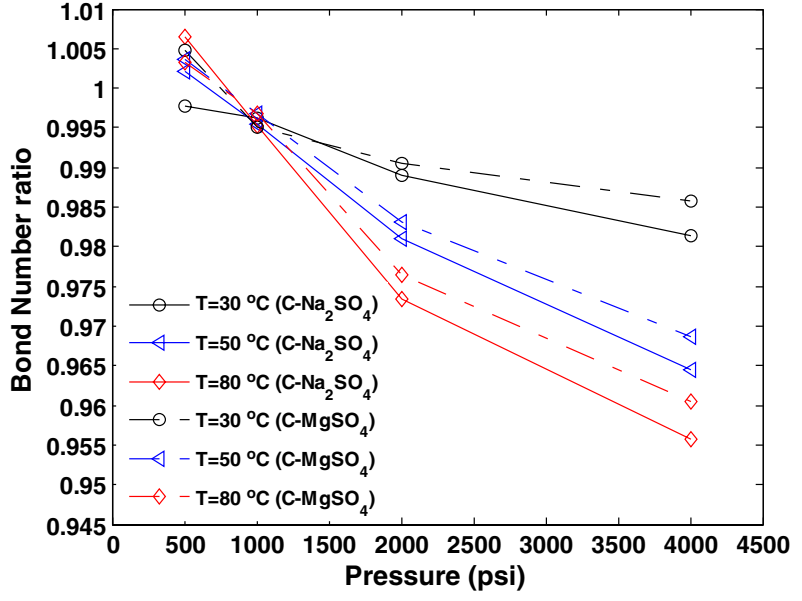

(b)

Fig. 9 Comparison of a swelling factor and $\mathbf{b}$ Bond number ratio in the presence of $15,000 \mathrm{ppm}$ of $\mathrm{Na}_{2} \mathrm{SO}_{4}$ and $15,000 \mathrm{ppm}$ of $\mathrm{MgSO}_{4}$ at different temperature and pressure condition

- The presence of divalent ions can significantly affect the cross over pressure and shift this value toward lower values from 1500 psi to 1000 psi which means $50 \%$ reduction in crossover pressure point.

- The presence of divalent ions, especially $\mathrm{Na}_{2} \mathrm{SO}_{4}$, may retard the solubility of $\mathrm{CO}_{2}$ in the brine solution. However, the presence of $\mathrm{MgSO}_{4}$ may lead to more undesired effect on the swelling factor due to stronger bonding between the $\mathrm{MgSO}_{4}$ and $\mathrm{CO}_{2}$ which prevent easier movement and partitioning of $\mathrm{CO}_{2}$ on the interface and consequently reduces the swelling factor compared with the solution comprised of $\mathrm{Na}_{2} \mathrm{SO}_{4}$.
- Ion type, temperature and $\mathrm{CO}_{2}$ content of aqueous phase showed remarkable effect on the mobility of $\mathrm{CO}_{2}$ molecules and their partitioning from aqueous phase towards oil phase and consequently on the swelling of crude oil during carbonated brine injection.

Open Access This article is licensed under a Creative Commons Attribution 4.0 International License, which permits use, sharing, adaptation, distribution and reproduction in any medium or format, as long as you give appropriate credit to the original author(s) and the source, provide a link to the Creative Commons licence, and indicate if changes were made. The images or other third party material in this article are 


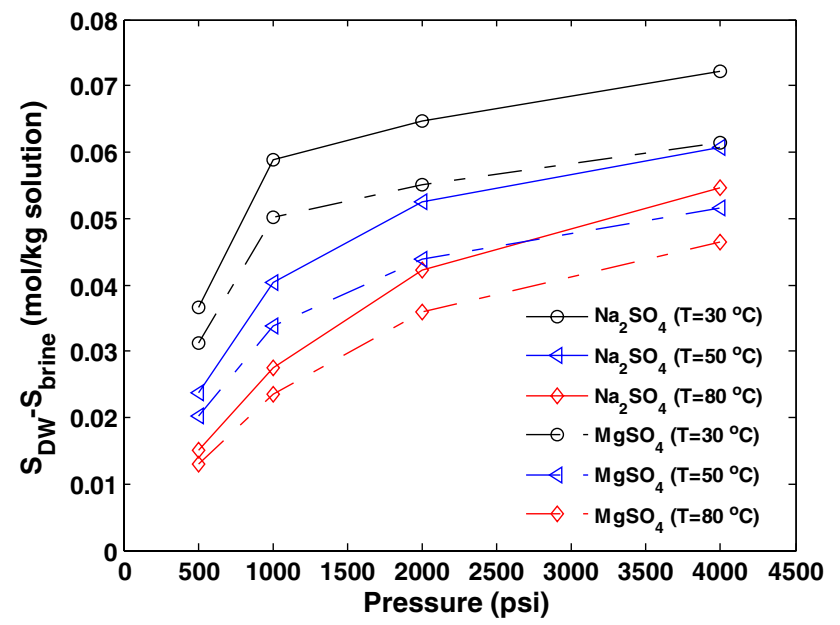

Fig. 10 Differences between solubility values of $\mathrm{CO}_{2}$ in the presence and absence of 15,000 ppm of $\mathrm{Na}_{2} \mathrm{SO}_{4}$ and $\mathrm{MgSO}_{4}$ at different temperature and pressure conditions obtained based on Duan model (Duan et al. 2006)

included in the article's Creative Commons licence, unless indicated otherwise in a credit line to the material. If material is not included in the article's Creative Commons licence and your intended use is not permitted by statutory regulation or exceeds the permitted use, you will need to obtain permission directly from the copyright holder. To view a copy of this licence, visit http://creativecommons.org/licenses/by/4.0/.

\section{References}

Abedini A, Mosavat N, Torabi F (2014) Determination of minimum miscibility pressure of crude oil- $\mathrm{CO}_{2}$ system by oil swelling/ extraction test. Energy Technol 2(5):431-439

Ahmadi MA et al (2016) Effect of operational parameters on the performance of carbonated water injection: experimental and numerical modeling study. J Supercrit Fluids 107:542-548

Austad T, RezaeiDoust A, Puntervold T (2010) Chemical mechanism of low salinity water flooding in sandstone reservoirs. In: SPE improved oil recovery symposium. Society of Petroleum Engineers

Barclay TH, Mishra S (2016) New correlations for $\mathrm{CO}_{2}$-Oil solubility and viscosity reduction for light oils. J Pet Explor Prod Technol 6(4):815-823

Duan Z, Sun R, Zhu C, Chou I-M (2006) An improved model for the calculation of $\mathrm{CO}_{2}$ solubility in aqueous solutions containing $\mathrm{Na}^{+}, \mathrm{K}^{+}, \mathrm{Ca}^{2+}, \mathrm{Mg}^{2+}, \mathrm{Cl}^{-}$, and $\mathrm{SO}^{2-}$. Mar Chem 98(2-4):131-139

Foroozesh J, Jamiolahmady M (2016) Simulation of carbonated water injection coreflood experiments: an insight into the wettability effect. Fuel 184:581-589

Foroozesh J, Jamiolahmady M, Sohrabi M (2016) Mathematical modeling of carbonated water injection for $\mathrm{EOR}$ and $\mathrm{CO}_{2}$ storage with a focus on mass transfer kinetics. Fuel 174:325-332

Honarvar B et al (2017) Experimental investigation of interfacial tension measurement and oil recovery by carbonated water injection: a case study using core samples from an iranian carbonate oil reservoir. Energy Fuels 31(3):2740-2748

Lashkarbolooki M, Ayatollahi S, Riazi M (2014) The impacts of aqueous ions on interfacial tension and wettability of an asphaltenic-acidic crude oil reservoir during smart water injection. J Chem Eng Data 59(11):3624-3634

Lashkarbolooki M, Riazi M, Ayatollahi S (2017) Effect of $\mathrm{CO}_{2}$ and natural surfactant of crude oil on the dynamic interfacial tensions during carbonated water flooding: experimental and modeling investigation. J Petrol Sci Eng 159:58-67

Lashkarbolooki M, Riazi M, Ayatollahi S (2018a) Effect of $\mathrm{CO}_{2}$ and crude oil type on the dynamic interfacial tension of crude oil/ carbonated water at different operational conditions. J Petrol Sci Eng 170:576-581

Lashkarbolooki M, Riazi M, Ayatollahi S (2018b) Experimental investigation of dynamic swelling and Bond number of crude oil during carbonated water flooding; effect of temperature and pressure. Fuel 214:135-143

Lashkarbolooki M, Hezave AZ, Ayatollahi S (2019) Swelling behavior of heavy crude oil during injection of carbonated brine containing chloride anion. J Mol Liq 276:7-14

Ligthelm DJ et al. (2009) Novel waterflooding strategy by manipulation of injection brine composition. In: EUROPEC/EAGE conference and exhibition. Society of Petroleum Engineers

McGuire P, Chatham J, Paskvan F, Sommer D, Carini F (2005) Low salinity oil recovery: an exciting new EOR opportunity for Alaska's North Slope. In: SPE western regional meeting. Society of Petroleum Engineers

Morrow NR, Tang G-Q, Valat M, Xie X (1998) Prospects of improved oil recovery related to wettability and brine composition. J Petrol Sci Eng 20(3-4):267-276

Mosavat N, Torabi F (2014) Experimental evaluation of the performance of carbonated water injection (CWI) under various operating conditions in light oil systems. Fuel 123:274-284

Mosavat N, Torabi F (2016) Micro-optical analysis of carbonated water injection in irregular and heterogeneous pore geometry. Fuel 175:191-201

Mosavat N, Abedini A, Torabi F (2014) Phase behaviour of $\mathrm{CO}_{2}-$ brine and $\mathrm{CO}_{2}$-oil systems for $\mathrm{CO}_{2}$ storage and enhanced oil recovery: experimental studies. Energy Procedia 63:5631-5645

Riazi M (2011) Pore scale mechanisms of carbonated water injection in oil reservoirs. Heriot-Watt University, Edinburg

Riazi M, Golkari A (2016) The influence of spreading coefficient on carbonated water alternating gas injection in a heavy crude oil. Fuel 178:1-9

Riazi M, Jamiolahmady M, Sohrabi M (2011a) Theoretical investigation of pore-scale mechanisms of carbonated water injection. $\mathrm{J}$ Petrol Sci Eng 75(3-4):312-326

Riazi M, Sohrabi M, Jamiolahmady M (2011b) Experimental study of pore-scale mechanisms of carbonated water injection. Transp Porous Media 86(1):73-86

Shakiba M, Ayatollahi S, Riazi M (2016) Investigation of oil recovery and $\mathrm{CO}_{2}$ storage during secondary and tertiary injection of carbonated water in an Iranian carbonate oil reservoir. J Petrol Sci Eng 137:134-143

Simon R, Graue D (1965) Generalized correlations for predicting solubility, swelling and viscosity behavior of $\mathrm{CO}_{2}$-crude oil systems. J Petrol Technol 17(01):102-106

Sohrabi M et al (2011a) Safe storage of $\mathrm{CO}_{2}$ together with improved oil recovery by $\mathrm{CO}_{2}$-enriched water injection. Chem Eng Res Des 89(9):1865-1872

Sohrabi M et al (2011b) Carbonated water injection (CWI)-A productive way of using $\mathrm{CO}_{2}$ for oil recovery and $\mathrm{CO}_{2}$ storage. Energy Procedia 4:2192-2199

Sohrabi M et al (2012) Coreflooding studies to investigate the potential of carbonated water injection as an injection strategy for improved oil recovery and $\mathrm{CO}_{2}$ storage. Transp Porous Media 91(1):101-121 
Tang G, Morrow NR (1997) Salinity, temperature, oil composition, and oil recovery by waterflooding. SPE Reserv Eng 12(04):269-276

Welker J (1963) Physical properties of carbonated oils. J Petrol Technol 15(08):873-876

Yang D, Tontiwachwuthikul P, Gu Y (2005) Interfacial tensions of the crude oil + reservoir brine $+\mathrm{CO}_{2}$ systems at pressures up to $31 \mathrm{MPa}$ and temperatures of $27 \mathrm{C}$ and $58 \mathrm{C}$. J Chem Eng Data 50(4):1242-1249

Zhao $\mathrm{H}$ et al (2015) Measurement and modeling of $\mathrm{CO}_{2}$ solubility in natural and synthetic formation brines for $\mathrm{CO}_{2}$ sequestration. Environ Sci Technol 49(3):1972-1980
Zolghadr A, Escrochi M, Ayatollahi S (2013) Temperature and composition effect on $\mathrm{CO}_{2}$ miscibility by interfacial tension measurement. J Chem Eng Data 58(5):1168-1175

Publisher's Note Springer Nature remains neutral with regard to jurisdictional claims in published maps and institutional affiliations. 